\title{
Challenges, Advantages and Disadvantages in Implementation of Ifrs 15 in Different Industries
}

\author{
Ivana Pavić ${ }^{1}$, Ivana Mamić Sačer ${ }^{2}$, Lajoš Žager ${ }^{3}$ \\ ${ }^{1,2,3}$ University of Zagreb/ Faculty of Economics and Business
}

\begin{abstract}
The accounting rules related to revenues' recognition and measurement have not been changed for many years, and have been listed in International Accounting Standard 18 - Revenues, which has been in use since 1984. Practice has shown that the standard is no longer an adequate basis for revenue recognition and therefore the International Accounting Standards Board (IASB) in cooperation with American FASB has created and published a new accounting standard that addresses the issue of revenue recognition - IFRS 15 - Revenues from Contracts with Customers. This standard supersedes the application of IAS 18 as of January 1, 2018. Since revenue is a very important element in determining the profit or loss of an entity and therefore its performance, preparers of financial statements should pay full attention to accounting principles related to revenues' recognition and measurement while preparing financial statements. New accounting standard for revenues introduces certain innovations in the field of revenue calculation as well as in time of revenues' recognition. These changes will have a significant impact on the amount of revenues for certain industries, such as the telecommunications and construction industry, which have significant share of revenues from contracts with customers. The aim of the research is to identify the challenges and problems that appears in the initial phase of application of a new standard on revenues such as; the need to consider a larger volume of documentation, inadequate existing IT infrastructure, multiple sources of documentation that must be considered in revenue recognition, including commercial, legal and financial documentation etc. In addition, we plan to identify benefits form the application of the new standard for the entities preparing the financial statements. In this context, it is expected to identify the sectors that have the most dilemmas in the application of this standard and to propose potential solutions to address these problems.
\end{abstract}

Keywords: advantages; disadvantages; challenges in implementation; IFRS 15; revenues 